Phenomenology \& Practice, Volume 13 (2019), No. 1, pp. 2-6

\title{
Editorial: On the Primacy of Language in Phenomenological Research
}

\author{
Erika Goble, NorQuest College, Edmonton, Canada \\ Email:Erika.Goble@norquest.ca
}

As I sit down to write my first editorial for Phenomenology \& Practice, I find myself hesitant, even stuck, facing the prospect of the page. After 15 years of studying phenomenology, conducting phenomenological research, and leading workshops, I still consider myself a novice. And it is not just me. It is a refrain I've heard from many of my colleagues: we are forever learning how to do phenomenology. While I realize an editorial need not be phenomenological, in itself, it should address a topic of concern for this field. It is daunting to face such a task. And as I stare at these words and the almost blank page, I am reminded of a concern, a question, that has emerged many times over the years in my own practice: why must they be words at all?

It is Saturday morning, and I'm scrolling through my Facebook newsfeed. As a subscriber to pretty much every phenomenology and phenomenology-inspired group on the platform, I quickly come across a notice of an upcoming conference taking place in Boston. The title of a presentation by Samantha Matherne catches my eye: "Are all artists phenomenologists? Perspectives from Edith Landmann-Kalischer and Maurice Merleau-Ponty." Knowing as many artists as phenomenologists and having studied artists and art practice, my immediate answer is "of course not" - this, I assert, despite my love for Merleau-Ponty's writing and the writing of all of the phenomenologists who explore the unique philosophical insights art can generate. No, I know both academically and bodily, that not all artists are phenomenologists, just as not all phenomenologists can turn their written text into literary prose. There are only a few who can be considered both.

There it is again: writing, text, prose.

The question that dogs me - and that has dogged me for years - is quite simply: why do our phenomenological texts need to be written texts at all? And, can they take other forms?

It may seem heresy to raise this question in an editorial of an academic journal dedicated to phenomenology writing. It is, at the very least, hypocritical to ask the question in writing. But it is one I want to present to the phenomenological community and written language is our most accepted mode of communication. So, please bear with me as I explore this question.

In an age when everyone is on the internet and we increasingly consume content through hand-held devices; when most scholars will agree that have taken a "pictorial turn" (Mitchell, 2005), where images saturate our society and become ubiquitous in communication, and we are increasingly accepting of the notion of film-as-philosophy (Loht, 2017); when academics are expected to be on Instagram and Twitter and the articles we publish are disseminated through electronic journals, some of which have even given up of the appearance of having a traditional journal form; when our funding agencies are increasing demanding we disseminate our results 
through non-traditional knowledge mobilization means, why do we remain firm in our belief that a phenomenological text must be comprised of the written word?

Perhaps I am a little closer to this question than most because my dissertation concerned the sublime experience of the visual image and, through the course of my study, I found one way to better understand the experience was through the image's creation. While this practice did add to my phenomenological insights and emerged as an integral reflective method in my study, I was not allowed to include the images in my actual dissertation. They were not considered "appropriate" by the academy. Now, I and my phenomenological study were not alone in facing this limitation. I had colleagues using different methodologies who were similarly prevented from including their visual content - whether it be a digital story, original art, or even beadworks - in their official dissertations. Oddly enough, however, poetry was allowed. So it seems that it was form rather than the fact that it was art, that was problematic to the institution.

I readily acknowledge this is question for all of academia, not just the practice of phenomenology. But for me, the acuity of the question is heightened in phenomenology when one considers that the forms we reject are simply other forms of language. Phenomenology seeks to create reflective texts, but why do we equate the notion of "text" exclusively with the written word?

I admit that in-roads are being made. This very journal published a selection of my images in an early article I published and Routledge agreed to include nearly all of the images when publishing the full text of my dissertation. I am grateful to both. However, the willingness of these two organizations are exceptions rather than the rule. We are a discipline where we must fight to include anything that looks different from the hundreds of historical phenomenological texts we've all read teaching ourselves how to do phenomenology.

And yet, this reluctance is incredibly strange when we consider how we present our work at conferences. Yes, we read a selection of our phenomenological text, but we supplement it with PowerPoint slides filled with images, quotes, and transitions. This is our default mode in presenting: while our text comes first and the visuals projected behind us secondary, they are still presented as a means of augmenting our audience's experience of our reading. To simply read one's paper at a conference is uncommon and strikes the audience as somewhat strange. A wholly read text requires a different kind of attention than the traditional phenomenological presentation set against PowerPoint.

This is not to say that the visual portions of presentations given at conferences are integral to the phenomenological texts. That only occurs infrequently. More often, one can remove the presentation entirely and the text, itself, is not impacted - and, indeed, many scholars do this as they prepare their text for publication. Rather, what I'm suggesting is that our presentation style might be a first step towards accepting that other forms of expression might be used to create phenomenological texts.

But what might they look like?

By happenstance, I was recently reminded of one possibility when I heard the announcement of Agnes Varda's death. Agnes Varda was an incomparable filmmaker. Her work is truly stunning. But one film has always stood out for me: The Gleaners and I (2000). The first time I saw it (and it was in an entirely non-phenomenological setting), I thought this is phenomenology in filmic form. The film is an exploration of the phenomenon of gleaning, in art, as a historical farming practice, as a contemporary act, and as an everyday experience that many of us engage in in various forms. Through Varda's different explorations of gleaning, we come to recognize the experience and ourselves in it. The film's form is both evocative and playful, 
embodying its subject in such as a way as to drawing out awareness that the documentary filmic form is yet another manifestation of gleaning. Varda constantly asks and makes us wonder "what is gleaning?" and through the film's consciously reflective practices, generate deep, meaningful, and often ethical insights into this strange but common practice. As a viewer and phenomenologist, each time I view it I bodily recognized The Gleaners and $I$ as being a phenomenological text, even as I struggle to comprehend how Varda managed to create it - the same response I have to strong phenomenological written texts. And when I consider it in light of the evaluation criteria set out by van Manen $(2014 ; 2017)$, its seems to more than meet our requirements to qualify as phenomenology. The film, in short, appears to embody phenomenological practices and be a form of visual phenomenological text. It is a phenomenological text in hiding because so few of us look for phenomenology in anything other than written forms.

If you haven't seen The Gleaners and I, I strongly encourage you to watch it. Watch it with an open mind to the possibility that phenomenology might just be possible in non-written forms. Film is only one potential form, but there could be many others.

But what happens to our practice, our discipline, if we open phenomenology as we practice it to other forms? What happens if we no longer require it only be a written text, but accept it in any communicative form? First, it would require us to develop new skills and potentially open our field to others whose expressive talents lay in areas other than writing. Those of us who current practice written phenomenology who want to engage in different forms would become novices once again. We would need to learn the grammar and form of the new language. As I have noted above, very few of us achieve artistry in our writing, even as we continuously work towards it. I suspect that even fewer would be competent phenomenological film-makers, phenomenological visual artists, or phenomenological musicians. To try to create a phenomenological film, for instance, would require phenomenologists to learn the visual language and visual practices of film. We work for years to become masters of a particular kind of written word; to change forms is to become a novice again who, despite being a fully competent phenomenological writing, might inadvertently create some very bad phenomenology in filmic form. The visual complicates, and subtle changes in the visual change meaning. Text does not directly translate to image. In working with Dylan van der Schiff to prepare his review of H. Peter Steeves' Beautiful, Bright, and Blinding: Phenomenological Aesthetics and the Life of Art, for publication, we realized we needed to clarify which film version of Beauty and the Beast Steeves' referred to. Depending on which film he meant, his meaning changed. In short, trying to be phenomenological film-makers or musicians may very much challenge our egos.

Then again, trying a different form might also make us better phenomenologists. Despite our best efforts, we tend to take language for granted. My colleague, Iris Yin, once observed that she found she was more careful with her phenomenological writing in English than native speakers or even how she wrote in Chinese. Because the English language wasn't a given, she noticed the subtleties of minor variances. Changing forms might demand a similar extension, a greater awareness, of what we currently take for granted in our phenomenological writing. Not knowing our new form might force us to attend to all of its minute nuances and the possibilities it enables for phenomenological expression.

More drastically, however, we would need to develop a whole new set of phenomenological practices for these new forms. If doing phenomenology is, at root, phenomenological writing and re-writing, undertaking phenomenology in a new form would require not just learning the new language we seek to use but also require we develop a whole set 
of creative methods to embody phenomenological texts in different formats. In writing, we have the anecdote-reflection cadence (Adams, 2014), but what is its equivalent in still photography or in music? Moreover, how can we understand this phenomenological element across the different phenomenological forms? This means that even those who choose to remain phenomenological writers would be impacted by this shift because we as a community would need an expanded understanding of our practice.

Invariably, I suspect the best practitioners of non-traditional phenomenological forms wouldn't be phenomenological writers at all, but creators - painters, documentary film-makers, musicians, artists - who find new possibilities with this philosophically-based research practice. This means that such an opening would also quickly challenge our acceptance of who is a phenomenological expert.

But even as considering phenomenology in non-text-based forms would present all of these challenges, the new forms would also invite greater engagement by the general public with phenomenology. People reluctant to read a text may find interest in phenomenology in another format. The Gleaners and $I$ is by no means Varda's most popular film. Even still, tens of thousands of people have seen it.

What, therefore, stops us from stepping forward, from trying to create other types of phenomenological forms? First and most simply, our history. We operate within a tradition that considers phenomenology to be a written form. That history is hard to overcome.

Second, few of us have the knowledge of how to create a phenomenological text of music. Or, if we do, we might simply be afraid that our peers won't understand it. To change forms is to change language, a language our peers do not fluently speak. How will our work be validated as phenomenology if other phenomenologists can't understand it? Third and, perhaps most damaging, is the risk that changing forms will cause us to lose credibility as academics. Here, I speak from personal experience.

I have only once created a phenomenological presentation where the visual images were as important as the text I read. For me, it was an experiment in a low-risk environment: a public presentation of student papers from our graduate phenomenology course. My topic, the experience of seeing an ugly face, simply lent itself to visual representation. The cadence of my reading corresponded to slide transitions. Key insights were punctuated by highly evocative images and slow fades to black. Just as in my writing, I cannot fully explain why it worked, but it worked: text and image seemed to become one in that presentation.

At the public event, there were my fellow classmates as well as several local professors, including one arts-based researcher. During the question period after my presentation, this professor informed both me and the room "that is not phenomenology, that is a piece of performance art." While I know she was offering her comment as a compliment, her words made me realize the risk of this kind of practice. Because it is different, people don't see if for what it is: visual phenomenology. Rather, it becomes relegated and, to a certain degree, diminished to the status of "mere art." The academic rigour disappears behind artistic engagement.

I have never published that presentation in visual form but, like so many phenomenologists, stripped out the visuals and turned it into an academic article. I am happy it is published, but I also see it as something of a loss. I recognize my cowardice in this action: I was more concerned about the academic recognition than pushing the boundaries of what I consider a genuine possibility for the field. I hope in the future I will have a similar opportunity and will choose differently. 
So, in conclusion, where does this leave us? With challenges and issues - some endemic to academia, some to our field, and some only at the persona level - but also with possibilities. I do believe that phenomenology can exist in other forms, even if we as practitioners still prefer the traditional written format. While academics have moved to publishing our articles on line, they still look very much like the printed journals from 200 years ago. As academics, we are creatures reluctant to embrace change and, as phenomenologists, we are even more bound to our written word. But what are the implications if we recognize that language can take many forms, that phenomenology is not inherently about writing but about a way of thinking and communication? What if we give up the primacy of the written word? Or at least begin to experiment with other possibilities. Embracing new forms might open us new avenues and new insights. Varda's film is much more revelatory than a written phenomenological text of gleaning, and her's is only one example. I am certain there are more, if we just look with phenomenological eyes. Similarly, we might find expanded understanding of own texts. It might provide some guidance to our reading of Kandinsky's writing and help us fully understand what Michel Henry saw in Kandinsky's work, what led him to travel the world following Kandinsky exhibits. And maybe, just maybe, it will bring a new audience to phenomenology. But more importantly, it might just make us better phenomenologists, even if all we do is write.

\section{References}

Adams, C. (2014). What's in a Name? The experience of the other in online classrooms. Phenomenology \& Practice, 1, 51-67.

Loht, S. (2017). Phenomenology of Film: A Heideggerian Account of the Film Experience. Lexington Books.

Mitchell, W.J.T. (2005). What do Pictures Want? Chicago \& London: University of Chicago Press.

van Manen, M. (2017). But is it phenomenology? Qualitative Health Research, 27(6), 775-779.

van Manen, M. (2014, 2016). Phenomenology of Practice: Meaning-Giving Methods in Phenomenological Research and Writing. London \& New York: Routledge.

Varda, A. (2000). The Gleaners and I. Cine-Tamaris. 